\title{
RESEARCH
}

Open Access

\section{LipoDDx: a mobile application for identification of rare lipodystrophy syndromes}

David Araújo-Vilar ${ }^{1,2^{*}}$ (D) Antía Fernández-Pombo ${ }^{1,2} \mathbb{D}$, Gemma Rodríguez-Carnero² ${ }^{\mathbb{D}}$,

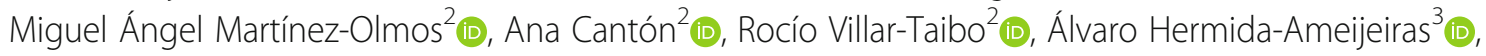
Alicia Santamaría-Nieto ${ }^{2}$, Carmen Díaz-Ortega ${ }^{2}$, Carmen Martínez-Rey ${ }^{4} \mathbb{D}$, Antonio Antela ${ }^{5}$, Elena Losada ${ }^{5}$, Andrés E. Muy-Pérez ${ }^{6}$ (D), Blanca González-Méndez ${ }^{1}$ (i) and Sofía Sánchez-Iglesias ${ }^{1}$ (D)

\begin{abstract}
Background: Lipodystrophy syndromes are a group of disorders characterized by a loss of adipose tissue once other situations of nutritional deprivation or exacerbated catabolism have been ruled out. With the exception of the HIV-associated lipodystrophy, they have a very low prevalence, which together with their large phenotypic heterogeneity makes their identification difficult, even for endocrinologists and pediatricians. This leads to significant delays in diagnosis or even to misdiagnosis.

Our group has developed an algorithm that identifies the more than 40 rare lipodystrophy subtypes described to date. This algorithm has been implemented in a free mobile application, LipoDDx ${ }^{\circledast}$. Our aim was to establish the effectiveness of LipoDDx ${ }^{\circledast}$.

Forty clinical records of patients with a diagnosis of certainty of most lipodystrophy subtypes were analyzed, including subjects without lipodystrophy. The medical records, blinded for diagnosis, were evaluated by 13 physicians, 1 biochemist and 1 dentist. Each evaluator first gave his/her results based on his/her own criteria. Then, a second diagnosis was given using LipoDDx ${ }^{\oplus}$. The results were analysed based on a score table according to the complexity of each case and the prevalence of the disease.

Results: LipoDDx ${ }^{\circledast}$ provides a user-friendly environment, based on usually dichotomous questions or choice of clinical signs from drop-down menus. The final result provided by this app for a particular case can be a low/high probability of suffering a particular lipodystrophy subtype. Without using LipoDDx ${ }^{\circledast}$ the success rate was $17 \pm 20 \%$, while with LipoDDx ${ }^{\circledast}$ the success rate was $79 \pm 20 \%(p<0.01)$.

(Continued on next page)
\end{abstract}

\footnotetext{
* Correspondence: david.araujo@usc.es

'Thyroid and Metabolic Diseases Unit (U.E.T.eM.), Department of Psychiatry, Radiology, Public Health, Nursing and Medicine (Medicine Area), Center for Research in Molecular Medicine and Chronic Diseases (CIMUS)-IDIS,

University of Santiago de Compostela, Avda. de Barcelona 3, 15706 Santiago de Compostela, Spain

${ }^{2}$ Endocrinology and Nutrition Division, Complexo Hospitalario Universitario de Santiago, Santiago de Compostela, Spain

Full list of author information is available at the end of the article
}

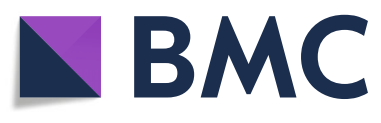

(c) The Author(s). 2020 Open Access This article is licensed under a Creative Commons Attribution 4.0 International License, which permits use, sharing, adaptation, distribution and reproduction in any medium or format, as long as you give appropriate credit to the original author(s) and the source, provide a link to the Creative Commons licence, and indicate if changes were made. The images or other third party material in this article are included in the article's Creative Commons licence, unless indicated otherwise in a credit line to the material. If material is not included in the article's Creative Commons licence and your intended use is not permitted by statutory regulation or exceeds the permitted use, you will need to obtain permission directly from the copyright holder. To view a copy of this licence, visit http://creativecommons.org/licenses/by/4.0/ The Creative Commons Public Domain Dedication waiver (http://creativecommons.org/publicdomain/zero/1.0/) applies to the data made available in this article, unless otherwise stated in a credit line to the data. 
(Continued from previous page)

Conclusions: LipoDDx ${ }^{\circledR}$ is a free app that enables the identification of subtypes of rare lipodystrophies, which in this small cohort has around $80 \%$ effectiveness, which will be of help to doctors who are not experts in this field. However, it will be necessary to analyze more cases in order to obtain a more accurate efficiency value.

Keywords: Lipodystrophy, Adipose tissue, Mobile application, Rare diseases

\section{Introduction}

Lipodystrophies are a group of very heterogenous diseases characterized by a lack of adipose tissue in the absence of catabolic state or caloric deprivation [1]. According to their etiology, lipodystrophies can be congenital or acquired and, depending on the extension of the lack of fat, they can be generalized, partial or localized. On the other hand, some complex conditions such as progeria and some autoinflammatory diseases can also be associated to lipoatrophy $[1,2]$.

Apart from HIV-associated lipodystrophy, the remaining subtypes are extremely infrequent. The real prevalence worldwide is not known but has been estimated at around 1.3-4.7 cases per million [3]. In addition, some particular subtypes are even more infrequent with only a few cases reported so far [4-8].

These two facts, the low prevalence and the clinical heterogeneity, make difficult the diagnosis. These diseases are, therefore, not well known, even among specialists like endocrinologists or pediatricians. Although there are no specific studies about this, based on our experience with more than 200 patients evaluated in the last 15 years, the delay in diagnosis is around 20 years, with a wide range from 1 to 70 .

At present, about 40 different subtypes of lipodystrophies have been described (Table 1), some of them with very similar characteristics, while others have clinical and/or biochemical, hematological, or particular image signs, although none is pathognomonic. The diagnosis of lipodystrophies is clinical [1]. On the other hand, more than 30 different genes associated with these disorders have been reported (Table 1). The identification of each subtype is critical since in more than a few cases a subtype can be related to a better or worse prognosis and/ or the appearance of certain comorbidities $[4,6,7,9]$.

In order to facilitate the identification of the different lipodystrophy subtypes among non-expert doctors in this field, our group has developed an application (app) for mobile devices, based on a personal development algorithm, resulting from our experience as a national reference centre for infrequent lipodystrophies and from in-depth study of the literature. This app, called LipoDDx ${ }^{\circ}$, provides, with a remarkable degree of accuracy, a diagnostic approach to the suspicion of lipodystrophy in a given patient.

\section{Subjects and methods}

The regional institutional review board, CEIC, approved this study, which was conducted according to the ethical guidelines of the Helsinki Declaration. Patients gave informed written consent for their participation in the study.

\section{The algorithm}

The algorithm is based on a decision tree, the basic skeleton of which is shown in Fig. 1. The detailed development of the algorithm is protected by industrial secrecy. The algorithm is presented as a decision tree based either on dichotomous questions (yes/no, yes/unknown/ no) or on menus of signs/symptoms that should be chosen according to the phenotype presented by the patient. Depending on the answers that the user chooses for a specific patient, the algorithm will reach a final result either suggesting a certain subtype of lipodystrophy (indicating if the probability of suffering from that particular lipodystrophy is high or low), or stating that he/ she does not suffer from lipodystrophy, or that the information provided does not enable a diagnosis.

\section{LipoDDx ${ }^{\circledast}$}

The software employed by the algorithm is based on the programming languages Typescript, which compiles to Javascript, HTML5 and SCSS, which compiles to CSS, allowing its installation on smartphones with IOS or Android operating systems. Other used software: Angular (version 7.x) - Licence MIT, Angular flex layout (version 7.x) - Licence MIT, Angular material (versión 7.x) - Licence MIT, ngx-translate (versión 11.x) - Licencia MIT, hammerjs (version 2.x) - Licence MIT, ng-simpleslideshow (version 1.x) - Licence MIT, Apache cordova (9.x) - Licence Apache v2.0. Project home page: https:// www.uetem.com/lipoddx/. Archived version: Registro General de la Propiedad Intelectual, registration seat number 03/2019/1209.

Like any app, LipoDDx ${ }^{\circ}$ is based on screens showing questions about the patient's signs or symptoms (Fig. 2). Sometimes photographs of characteristic clinical signs have been incorporated to facilitate their identification (Fig. 2c). Depending on the user's answers, new screens will appear with further questions until a final result is reached.

On the left-hand side of the screen we have located a drop-down menu where relevant information related to intellectual property credits is provided, a disclaimer that the app can never replace the criteria of a physician, information about lipodystrophies reference centres and 
Table 1 Lipodystrophy subtypes (adapted from (2))

\section{Congenital}

1.1 Generalized

Type 1 CGL (AGPAT2, recessive, OMIM \#608594)

Type 2 CGL (BSCL2, recessive, OMIM \#269700)

Type 3 CGL (CAV1, recessive, OMIM \#612526)

Type 4 CGL (PTRF, recessive, OMIM \#613327)

PPARG -associated CGL (recessive)

Progressive Encephalopathy with/without lipodystrophy (BSCL2, recessive, OMIM: \#615924)

1.2 Partial

Type 1 FPLD (Köbberling syndrome; genes unknown, OMIM \%608, 600)

Type 2 FPLD (Dunnigan disease; LMNA, (co-)dominant, OMIM \#151660)

Type 3 FPLD (PPARG, dominant, OMIM \#604367)

Type 4 FPLD (PLIN1, dominant, OMIM \#613877)

Type 5 FPLD (CIDEC, recessive, OMIM \#615238)

Type 6 FPLD (LIPE, recessive, OMIM \#615980)

Type 7 FPLD with congenital cataracts, and neurodegeneration (CAV1, dominant, OMIM \#606721)

AKT2-linked lipodystrophy (dominant)

MFN2 associated FPLD (recessive)

ADRA2A associated FPLD (dominant)

1.3 Systemic

1.3.1 Progeroid syndromes

Hutchinson-Gilford progeria syndrome (LMNA, dominant, OMIM \#176670)

Néstor-Guillermo progeria syndrome (BANF1, recessive, OMIM \#614008)

Atypical Werner syndrome and atypical progeroid syndrome (de novo, LMNA-associated)

Werner syndrome (RECQL2, recessive, OMIM \#277700)

Type A mandibuloacral dysplasia (LMNA, recessive, OMIM \#248370)

Type B mandibuloacral dysplasia (ZMPSTE24, recessive, OMIM \#608612)

SHORT syndrome (PIK3R1, dominant, OMIM \#269880)

MDPL syndrome (POLD1, dominant, OMIM \#615381)

Keppen-Lubinsky syndrome (KCNJ6, dominant, OMIM \#614098)

Ruijs-Aalfs syndrome (SPRTN, recessive, OMIM \#616200)

Cockayne syndrome (ERCC6,recessive, OMIM \#133540)

Cockayne syndrome (ERCC6, recessive, OMIM \#216400)

Marfan syndrome with neonatal progeroid -like lipodystrophy (FBN1, dominant, OMIM \#616914)

CAV1-associated neonatal onset lipodystrophy syndrome (dominant)

PCYT1A lipodystrophy (recessive)

Wiedemann Rautenstrauch syndrome (POLR3A, recessive, OMIM \#264090)
Table 1 Lipodystrophy subtypes (adapted from (2)) (Continued)

Fontaine progeroid syndrome (SLC25A24, de novo, OMIM \# 612289)

1.3.2 Autoinflammatory syndromes

PRAAS1 (PSMB8, recessive or digenic with PSMA3 or PSMB4, OMIM \#256040)

PRAAS2 (POMP, dominant, OMIM \#618048)

PRAAS3 (PSMB4, recessive or digenic with PSMB9, OMIM \# 617591)

Panniculitis-associated lipodystrophy (OTULIN, recessive, OMIM \#617099)

1.3.3 Others

Optic atrophy, cataracts, lipodystrophy/lipoatrophy, peripheral neuropathy (OPA3, dominant, OMIM \#165300)

\section{Acquired}

2.1 Generalized

Acquired Generalized Lipodystrophy, idiopathic

Acquired Generalized Lipodystrophy, autoimmune

Acquired Generalized Lipodystrophy, panniculitis

2.2 Partial (excluding HIV associated lipodystrophy)

Acquired partial lipodystrophy (Barraquer-Simons syndrome)

Lipodystrophy associated with total body irradiation and

hematopoietic stem cell transplant

2.3 Localized

CGL congenital generalized lipodystrophy, FPLD familial partial lipodystrophy, PRAAS Proteasome-associated auto-inflammatory syndrome, MDPL mandibular hypoplasia, deafness, progeroid features, and lipodystrophy syndrome

patient advocacy groups, as well as a link to the European lipodystrophy registry (http://134.60.15.143:8080/ login.xhtml).

\section{Validation}

To evaluate the accuracy of LipoDDx ${ }^{\circ}$ we selected 40 clinical cases (Table 2), 19 from our unit and 21 from the scientific literature [5-7, 10-25]. Thirty-seven of them presented a diagnosis of certainty of some subtype of lipodystrophy and 3 did not present any kind of lipodystrophy. These cases, obviously without showing the diagnosis, were provided to 15 evaluators (13 physicians, specialists in endocrinology, pediatrics or internal medicine, one biochemist and one dentist). Except one, the other 14 lacked clinical experience in the management of infrequent lipodystrophies. All of them were encouraged not to study anything related to the diagnosis of lipodystrophies. Each examiner had to read each case and give their own diagnosis after which they were asked to use LipoDDx ${ }^{\circ}$. The results of the evaluation of the 40 cases, both those obtained based on their own knowledge and those provided by the app, were sent anonymously to a team member for further statistical analysis. 

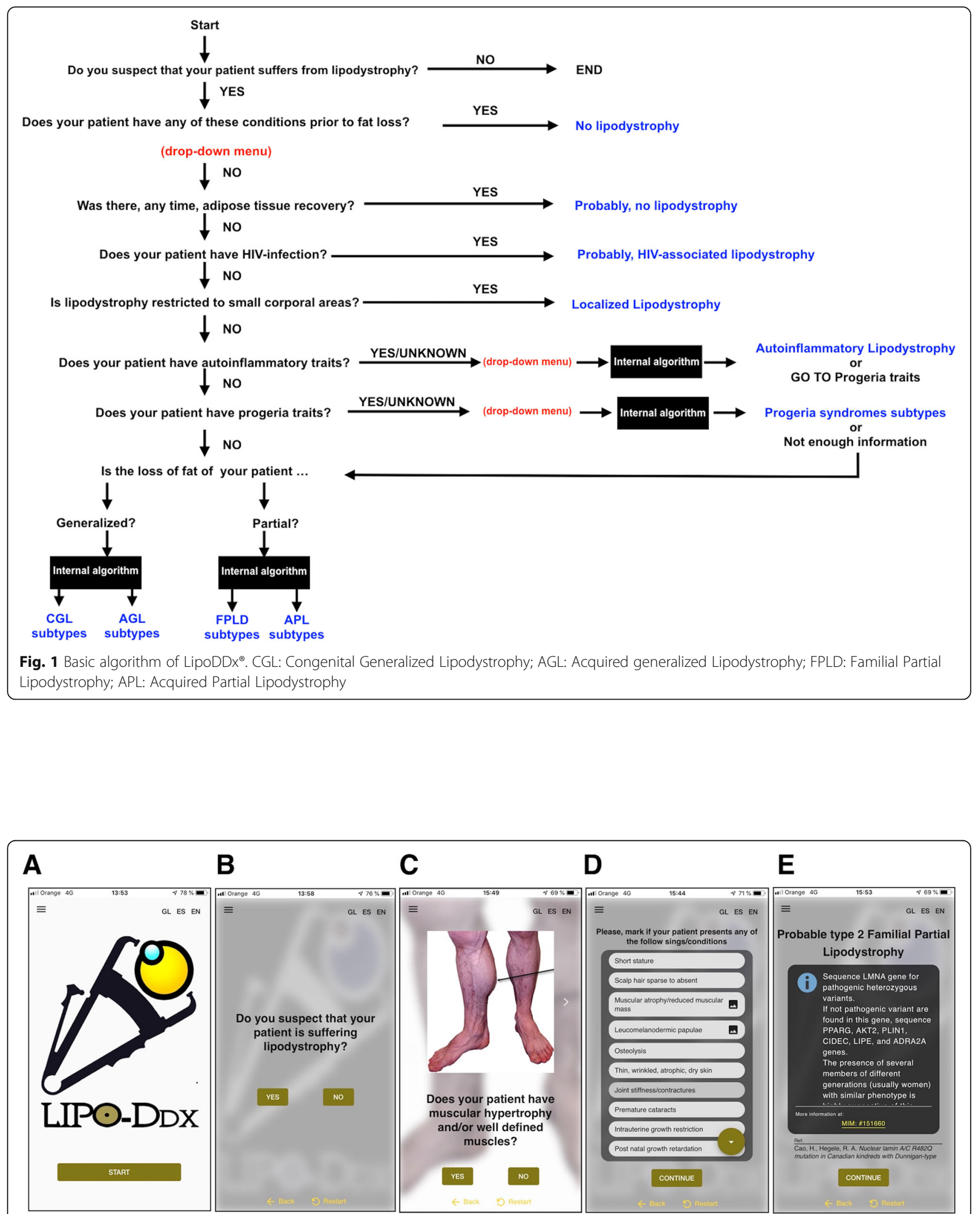

Fig. 2 Different screens of LipoDDx ${ }^{\oplus}$. a First screen. b Screen with dichotomous question. $\mathbf{c}$ Screen with a picture of a characteristic sign of some lipodystrophies. $\mathbf{d}$ Screen with a drop-down menu for choosing different signs. e Screen of a final results indicating the possible lipodystrophy subtype. In this case, information is given about the genes that should be sequenced and also links to OMIM, and bibliographic references 
Table 2 Analysed cases for LipoDDX ${ }^{\circledR}$ validation

\begin{tabular}{|c|c|c|}
\hline Case & Diagnosis & Reference \\
\hline$\# 1$ & Type 2 Familial Partial Lipodystrophy & Own case \\
\hline \#2 & Acquired Generalized Lipodystrophy & Own case \\
\hline \#3 & Acquired Partial Lipodystrophy & Own case \\
\hline \#4 & Type 6 Familial Partial Lipodystrophy & Ref.\# [6] \\
\hline \#5 & Keppen-Lubinsky syndrome & Ref.\# [10] \\
\hline \#6 & Type 3 Familial Partial Lipodystrophy & Ref.\# [11] \\
\hline$\# 7$ & Lipodystrophy associated with hematopoietic stem cell transplant & Own case \\
\hline \#8 & Progressive Encephalopathy with/without lipodystrophy & Own case \\
\hline \#9 & Type 2 congenital generalized lipodystrophy & Own case \\
\hline$\# 10$ & Type 1 congenital generalized lipodystrophy & Own case \\
\hline$\# 11$ & Marfan syndrome with neonatal progeroid -like lipodystrophy & Ref.\# [12] \\
\hline$\# 12$ & Type 6 Familial Partial Lipodystrophy & Ref.\# [6] \\
\hline$\# 13$ & PRAAS1 & Ref.\# [13] \\
\hline \#14 & SHORT syndrome & Own case \\
\hline$\# 15$ & MDPL syndrome & Ref.\# [14] \\
\hline \#16 & Thyrotoxicosis & Own case \\
\hline$\# 17$ & Werner syndrome & Own case \\
\hline \#18 & Keppen-Lubinsky syndrome & Ref.\# [10] \\
\hline \#19 & Type 3 Familial Partial Lipodystrophy & Ref.\# [15] \\
\hline \#20 & Type 4 Familial Partial Lipodystrophy & Ref.\# [16] \\
\hline \#22 & Anorexia nervosa & Ref.\# [17] \\
\hline \#23 & Localized lipodystrophy & Own case \\
\hline \#24 & Cockayne syndrome & Ref.\# [18] \\
\hline \#25 & Type 5 Familial Partial Lipodystrophy & Ref.\# [19] \\
\hline \#26 & Acquired Generalized Lipodystrophy & Own case \\
\hline \#27 & Type 2 Familial Partial Lipodystrophy & Own case \\
\hline \#28 & MFN2 associated FPLD & Ref.\# [7] \\
\hline \#29 & Type 4 congenital generalized lipodystrophy & Ref.\# [20] \\
\hline \#30 & Néstor-Guillermo progeria syndrome & Ref.\# [21] \\
\hline \#31 & Acquired Partial Lipodystrophy & Own case \\
\hline \#32 & Atypical progeroid syndrome & Own case \\
\hline \#33 & Mental disorder & Own case \\
\hline$\# 34$ & Hutchinson-Gilford progeria syndrome & Own case \\
\hline \#35 & Type 1 congenital generalized lipodystrophy & Own case \\
\hline \#36 & ADRA2A associated FPLD & Ref.\# [5] \\
\hline \#37 & Fontaine progeroid syndrome & Ref.\# [22] \\
\hline \#38 & Type A mandibuloacral dysplasia & Ref.\# [23] \\
\hline \#39 & Wiedemann Rautenstrauch syndrome & Ref.\# [24] \\
\hline$\# 40$ & Type 1 Familial Partial Lipodystrophy & Own case \\
\hline
\end{tabular}

\section{Statistical analysis}

Since this app is not a procedure to establish a nondisease/disease dichotomous situation, it is not possible to calculate the positive and negative predictive value. On the other hand, given the low prevalence of these disorders and the small number of cases analysed, sensitivity and specificity values should not be used. In this specific case, the method used to validate our app was that of a table of variable scores (Table 1S-supplementary file), ranging between -10 and 40 points for each 
case. The highest values were assigned if the diagnosis was correct in the less prevalent and more complex cases, while the lowest scores were assigned to failure in the diagnosis of the simplest cases. The highest score per evaluator was 989 points, which would indicate that the diagnosis was correct in $100 \%$ of the cases. The scores were transformed into percentages and the comparison between the percentage of successes without using LipoDDx ${ }^{\circ}$ and using LipoDDx ${ }^{\circ}$ was performed using the Wilcoxon test. Significant differences were considered with a $p<0.05$. All statistical analyses were performed using SPSS for Mac (release 22.0; SPSS, Chicago, IL, USA).

\section{Results}

\section{App environment}

LipoDDx ${ }^{\circ}$ is an app with a user-friendly environment compatible with iOS and Android operating systems and can be downloaded for free from the Apple Store (https://apps.apple.com/es/app/lipoddx/id1474797838)

and Google Play (https://play.google.com/store/apps/ details?id=araujo.lipoddx). It comes in three languages (English, Spanish and Galician) which can be selected in the upper right corner of the screen.

The use of the app begins with the question "do you suspect that your patient suffers from lipodystrophy?" (Fig. 2b). Depending on the response, successive screens will appear with different questions related to the patient's symptoms and signs. Although many questions are dichotomous, sometimes the user will have to choose among a list of signs/symptoms (Fig. 2d). At the end of the process, a final screen is reached in which the lipodystrophy subtype that the patient may suffer from is suggested (Fig. 2e) or it is stated that there is not enough data to reach a diagnosis. If it is possible to identify the subtype, the app also provides information on the gene or genes that would be recommended to sequence (in the case of congenital lipodystrophies), other complementary tests that would be helpful in the diagnosis (eg. the determination of $\mathrm{C} 3$ complement plasma levels in Barraquer-Simons syndrome), as well as links to OMIM or ORPHANET (Fig. 2e).

\section{Results of the validation}

The results of the validation are shown in Fig. 3. Of the 40 patients analysed, the evaluators made the correct diagnosis by themselves in $17 \pm 20 \%$ cases [range: 0 $58 \%$, while with LipoDDx $^{\circ}$ the success rate was $79 \pm$ 20\% [range: $60-100 \%$ ] $(p<0.01)$.

\section{Discussion}

Although without scientific evidence, the perception of experts in infrequent lipodystrophies is that there is a generalized lack of knowledge even among health-care specialists. This fact leads, as in many other rare diseases, to a significant delay in diagnosis, which in our

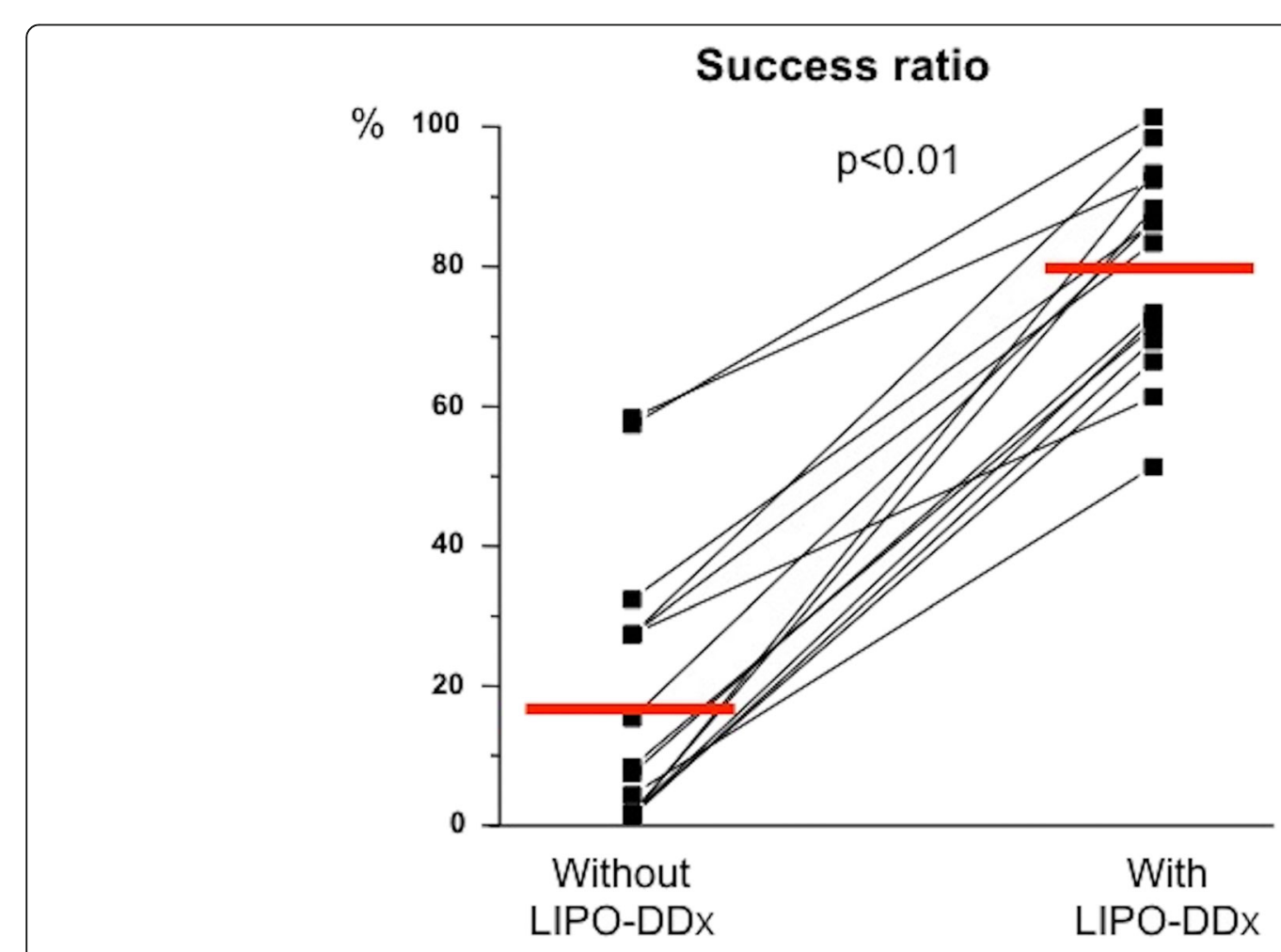

Fig. 3 Success rate of evaluators when comparing their own diagnosis (without LipoDDx ${ }^{\circledast}$ ) with the use of LipoDDx ${ }^{\circledR}$ 
experience is on average 20 years, mainly in partial lipodystrophies. Moreover, lipodystrophy is not a single disease but a heterogeneous set of disorders characterized by a generalized or partial absence of adipose tissue, with unique clinical manifestations, different associated co-morbidities, and a variable prognosis according to the subtype. There are few hospitals in the world with reference units specialized in lipodystrophies, and even in these units the number of patients who are diagnosed and followed do not exceed two or three hundred per centre in the best case scenario. On the other hand, the diagnosis of lipodystrophies is exclusively clinical [1], there is no complementary test or biological marker that allows for their identification.

All of this undermines the health and welfare of the patients, who are not diagnosed or, even worse, misdiagnosed, which leads to inadequate treatments and an aggravation of their complications.

Based on these premises and given the widespread use of smartphones, we have developed a mobile app, aimed at physicians, based on a personal algorithm that enables all the lipodystrophy subtypes described to date to be identified with remarkable efficiency.

The number of medical apps is huge. According to Piran et al. [26] more than 30,000 medical apps are available in Apple Store. As far as we know, LipoDDx ${ }^{\circ}$ would be the first one that allows an accurate diagnostic approach to a large and heterogeneous group of rare diseases.

Although a success rate close to $80 \%$ can be considered a good result, we believe that this can be improved as practitioners become more familiar with the app. Furthermore, we intend to improve LipoDDx ${ }^{\circ}$ in successive versions as new genes are discovered and new lipodystrophy subtypes are described. At the same time, the dissemination of the app in congresses and medical meetings and via social networks will probably lead to the reception of users input, which will allow us to refine the algorithm.

Realistically, it seems unlikely that any doctor will have enough experience to adequately focus the diagnosis of a certain subtype of lipodystrophy. We believe that LipoDDx ${ }^{\circ}$ can be a useful and affordable tool for any practitioner anywhere in the world faced with a patient with suspicion of loss of adipose tissue.

As an added value, LipoDDx ${ }^{\circ}$ provides information on expert centers in Europe and abroad that will undoubtedly serve to request second opinions or to defer patients with complex diagnoses to these centres. In addition, information is also provided on associations of patients with lipodystrophy, both European and North American. This app will therefore not only be useful to doctors but also to patients and their families.

\section{Conclusions}

LipoDDx ${ }^{\bullet}$ is a free mobile application for the identification of different subtypes of infrequent lipodystrophies, which is effective in approximately $80 \%$ of cases in this first validation process. However, it will be necessary to analyze more cases in order to obtain a more accurate efficiency value. LipoDDx ${ }^{\circ}$ is, to the best of our knowledge, the first app to allow a precise and rapid identification of a set of heterogenous rare diseases without having in-deep knowlegements in dysmorphology, aimed not only to specialists, but also general practitioners.

\section{Supplementary information}

Supplementary information accompanies this paper at https://doi.org/10. 1186/s13023-020-01364-1.

Additional file 1: Table 1S. Score table. The result obtained by a particular evaluator for a particular case will receive different score according to the difficulty of the diagnosis. Because the degree of difficulty in the diagnosis is not equal in all of the cases, we assigned a different score, ranged between -10 to 40, according to the "difficulty" for diagnosing. For instance, if a patient has a loss of fat because she had anorexia nervosa but the evaluator considered that she suffered any subtype of generalized lipodystrophy, the score will be negative, and the opposite is true, if a patient suffered a extremely infrequent lipodystrophy, with a complicated phenotype (for instance, Wiedemann Rautenstrauch syndrome) and the evaluator achieved a correct diagnose, the score will be high. Then, we add all the scores of each evaluator, transformed in percentage, and compared the results obtained based on his/her on knowledges with those provided by LipoDDX.

\section{Abbreviations}

AGL: Acquired Generalized Lipodystrophy; APL: Acquired Partial Lipodystrophy; app: mobile application; CEIC: Comité de Ética de Investigación Clínica de Galicia; CGL: Congenital Generalized Lipodystrophy; CGL1: Type 1 Congenital Generalized Lipodystrophy; CGL2: Type 2 Congenital Generalized Lipodystrophy; CGL4: Type 4 Congenital Generalized Lipodystrophy; CSS: Cascading Style Sheets; FPLD: Familial Partial

Lipodystrophy; FPLD1: Type 1 Familial Partial Lipodystrophy.; FPLD2: Type 2 Familial Partial Lipodystrophy; FPLD4: Type 4 Familial Partial Lipodystrophy; FPLD5: Type 5 Familial Partial Lipodystrophy; FPLD6: Type 6 Familial Partial Lipodystrophy; IOS: iPhone Operative System; HGPS: Hutchinson-Gilford progeria syndrome; HIV: Human immunodeficiency viruses; HTML: HyperText Markup Language; MADA: Type A mandibuloacral dysplasia;

MDPL: Mandibular hypoplasia, deafness, progeroid features, and lipodystrophy syndrome; MIT: Massachusetts Institute of Technology; OMIM: Online Mendelian Inheritance in Man; PELD: Progressive

Encephalopathy with/without Lipodystrophy; PRAAS: Proteasome-associated auto-inflammatory syndrome; SCSS: Sassy CSS; SHORT: Short stature,

hyperextensibility, hernia, ocular depression, Rieger anomaly, and teething delay; SPSS: Statistical Package for the Social Sciences

\section{Acknowledgements}

We want to thanks Prof. Wenceslao Manteiga and Prof. Manuel FebreroBande from the Statistical Department of the University of Santiago de Compostela for their help in the statistical approach of this work.

\section{Authors' contributions}

DA-V was principal investigator, led the study, design of the study and the data analysis, drafted the paper, and is responsible for the overall content as guarantor. AF-P analyzed the blind clinical cases, apply the app, and commented on and approved the manuscript. GR-C analyzed the blind clinical cases, apply the app, and commented on and approved the manuscript. MAM-O analyzed the blind clinical cases, apply the app, and commented on and approved the manuscript. AC analyzed the blind clinical cases, apply the app, and commented on and approved the manuscript. RV-T analyzed the 
blind clinical cases, apply the app, and commented on and approved the manuscript. AH-A analyzed the blind clinical cases, apply the app, and commented on and approved the manuscript. AS-N analyzed the blind clinical cases, apply the app, and commented on and approved the manuscript. CD$\mathrm{O}$ analyzed the blind clinical cases, apply the app, and commented on and approved the manuscript. CM-R analyzed the blind clinical cases, apply the app, and commented on and approved the manuscript. AA analyzed the blind clinical cases, apply the app, and commented on and approved the manuscript. EL analyzed the blind clinical cases, apply the app, and commented on and approved the manuscript. AEM-P analyzed the blind clinical cases, apply the app, and commented on and approved the manuscript. BG$\mathrm{M}$ analyzed the blind clinical cases, apply the app, and commented on and approved the manuscript. SS-I analyzed the blind clinical cases, apply the app, and commented on and approved the manuscript. The authors read and approved the final manuscript.

\section{Funding}

Project financed with an intramural grant from the Xunta de Galicia, ED341b 2017/19. S.S-I was awarded a Research Fellowship, granted by the Asociación Española de Familiares y Afectados de Lipodistrofias (AELIP).

\section{Availability of data and materials}

LipoDDx can be download from Apple Store or Google Play.

The datasets used and/or analysed during the current study are available from the corresponding author on reasonable request.

\section{Ethics approval and consent to participate}

The regional institutional review board, CEIC, approved this study, which was conducted according to the ethical guidelines of the Helsinki Declaration.

\section{Consent for publication}

No information about personal or clinical data of the studied patients which allow their identification have been included in this manuscript.

\section{Competing interests}

The authors declare that they have no competing interests.

\section{Author details}

${ }^{1}$ Thyroid and Metabolic Diseases Unit (U.E.T.eM.), Department of Psychiatry, Radiology, Public Health, Nursing and Medicine (Medicine Area), Center for Research in Molecular Medicine and Chronic Diseases (CIMUS)-IDIS, University of Santiago de Compostela, Avda. de Barcelona 3, 15706 Santiago de Compostela, Spain. ${ }^{2}$ Endocrinology and Nutrition Division, Complexo Hospitalario Universitario de Santiago, Santiago de Compostela, Spain. ${ }^{3}$ Unit of Diagnosis and Treatment of Congenital Metabolic Diseases, Service of Neonatology, Department of Pediatrics, Complexo Hospitalario Universitario, CIBERER, Health Research Institute of Santiago de Compostela (IDIS), Santiago de Compostela, Spain. ${ }^{4}$ Internal Medicine Division, Complexo Hospitalario Universitario, Santiago de Compostela, Spain. ${ }^{5}$ Infectious Diseases Unit, Complexo Hospitalario Universitario, Santiago de Compostela, Spain. ${ }^{6}$ Paediatrics Division. Complexo Hospitalario Universitario, Santiago de Compostela, Spain.

\section{Received: 1 November 2019 Accepted: 18 March 2020} Published online: 02 April 2020

\section{References}

1. Brown RJ, Araujo-Vilar D, Cheung PT, Dunger D, Garg A, Jack M, Mungai L, Oral EA, Patni N, Rother Kl, von Schnurbein J, Sorkina E, Stanley T, Vigouroux C, Wabitsch M, Williams R, Yorifuji T. The Diagnosis and Management of Lipodystrophy Syndromes: A Multi-Society Practice Guideline. J Clin Endocrinol Metab. 2016;101:4500-11. https://doi.org/10.1210/jc.2016-2466.

2. Araújo-Vilar D, Santini F. Diagnosis and treatment of lipodystrophy: a stepby-step approach. J Endocrinol Investig. 2019;42:61-73. https://doi.org/10. 1007/s40618-018-0887-z.

3. Chiquette E, Oral EA, Garg A, Araújo-Vilar D, Dhankhar P. Estimating the prevalence of generalized and partial lipodystrophy: findings and challenges. Diabetes Metab Syndr Obes. 2017;10:375-83. https://doi.org/10. 2147/DMSO.S130810.

4. Guillén-Navarro E, Sánchez-Iglesias S, Domingo-Jiménez R, Victoria B, RuizRiquelme A, Rábano A, Loidi L, Beiras A, González-Méndez B, Ramos A,
López-González V, Ballesta-Martínez MJ, Garrido-Pumar M, Aguiar P, Ruibal A, Requena JR, Araújo-Vilar D. A new seipin-associated neurodegenerative syndrome. J Med Genet. 2013;50:401-9. https://doi.org/10.1136/jmedgenet2013-101525.

5. Garg A, Sankella S, Xing C, Agarwal AK. Whole-exome sequencing identifies ADRA2A mutation in atypical familial partial lipodystrophy. JCI Insight. 2016; 1. https://doi.org/10.1172/jci.insight.86870.

6. Zolotov S, Xing C, Mahamid R, Shalata A, Sheikh-Ahmad M, Garg A. Homozygous LIPE mutation in siblings with multiple symmetric lipomatosis, partial lipodystrophy, and myopathy. Am J Med Genet A. 2017;173:190-4. https://doi.org/10.1002/ajmg.a.37880.

7. Rocha N, Bulger DA, Frontini A, Titheradge H, Gribsholt SB, Knox R, Page M, Harris J, Payne F, Adams C, Sleigh A, Crawford J, Gjesing AP, Bork-Jensen J, Pedersen O, Barroso I, Hansen T, Cox H, Reilly M, Rossor A, Brown RJ, Taylor SI, McHale D, Armstrong M, Oral EA, Saudek V, O'Rahilly S, Maher ER, Richelsen B, Savage DB, Semple RK. Human biallelic MFN2 mutations induce mitochondrial dysfunction, upper body adipose hyperplasia, and suppression of leptin expression. Elife. 2017;6. https://doi.org/10.7554/eLife.23813.

8. Jéru I, Vantyghem MC, Bismuth E, Cervera P, Barraud S, PLIN1-Study Group, Auclair M, Vatier C, Lascols O, Savage DB, Vigouroux C. Diagnostic challenge in PLIN1-associated Familial Partial Lipodystrophy. J Clin Endocrinol Metab. 2019;104:6025-32. https://doi.org/10.1210/jc.2019-00849.

9. Akinci B, Oral EA, Neidert A, Rus D, Cheng WY, Thompson-Leduc P, Cheung HC, Bradt P, Foss de Freitas MC, Montenegro RM, Fernandes VO, Cochran E, Brown RJ. Comorbidities and Survival in Patients with Lipodystrophy: An International Chart Review Study. J Clin Endocrinol Metab. 2019;104(11): 5120-35. https://doi.org/10.1210/jc.2018-02730.

10. Masotti A, Uva P, Davis-Keppen L, Basel-Vanagaite L, Cohen L, Pisaneschi E, Celluzzi A, Bencivenga P, Fang M, Tian M, Xu X, Cappa M, Dallapiccola B. Keppen-Lubinsky syndrome is caused by mutations in the inwardly rectifying K+ channel encoded by KCNJ6. Am J Hum Genet. 2015;96:295300. https://doi.org/10.1016/j.ajhg.2014.12.011.

11. Agarwal AK, Garg A. A novel heterozygous mutation in peroxisome proliferator-activated receptor-gamma gene in a patient with familial partial lipodystrophy. J Clin Endocrinol Metab. 2002;87:408-11. https://doi.org/10. 1210/jcem.87.1.8290.

12. Passarge E, Robinson PN, Graul-Neumann LM. Marfanoid-progeroidlipodystrophy syndrome: a newly recognized fibrillinopathy. Eur J Hum Genet. 2016;24:1244-7. https://doi.org/10.1038/ejhg.2016.6.

13. Garg A, Hernandez MD, Sousa AB, Subramanyam L, Martínez de Villarreal L, dos Santos HG, Barboza O. An autosomal recessive syndrome of joint contractures, muscular atrophy, microcytic anemia, and panniculitisassociated lipodystrophy. J Clin Endocrinol Metab. 2010;95:E58-E63. https:// doi.org/10.1210/jc.2010-0488

14. Pelosini C, Martinelli S, Ceccarini G, Magno S, Barone I, Basolo A, Fierabracci P, Vitti P, Maffei M, Santini F. Identification of a novel mutation in the polymerase delta 1 (POLD1) gene in a lipodystrophic patient affected by mandibular hypoplasia, deafness, progeroid features (MDPL) syndrome. Metabolism. 2014;63:1385-9. https://doi.org/10.1016/j. metabol.2014.07.010.

15. Guettier JM, Park JY, Cochran EK, Poitou C, Basdevant A, Meier M, Clément K, Magré J, Gorden P. Leptin therapy for partial lipodystrophy linked to a PPAR-gamma mutation. Clin Endocrinol. 2008;68:547-54. https://doi.org/10. 1111/j.1365-2265.2007.03095.x

16. Gandotra S, Le Dour C, Bottomley W, Cervera P, Giral P, Reznik Y, Charpentier G, Auclair M, Delépine M, Barroso I, Semple RK, Lathrop M, Lascols O, Capeau J, O'Rahilly S, Magré J, Savage DB. Vigouroux C Perilipin deficiency and autosomal dominant partial lipodystrophy. N Engl J Med. 2011;364:740-8. https://doi.org/10.1056/NEJMoa1007487.

17. Crisp AH, Roberts FJ. A case of anorexia nervosa in a male. Postgrad Med J. 1962;38:350-3. https://doi.org/10.1136/pgmj.38.440.350.

18. Taghdiri M, Dastsooz H, Fardaei M, Mohammadi S, Farazi Fard MA, Faghihi MA. A novel mutation in ERCC8 gene causing Cockayne syndrome. Front Pediatr. 2017:5:169. https://doi.org/10.3389/fped.2017.00169.

19. Rubio-Cabezas O, Puri V, Murano I, Saudek V, Semple RK, Dash S, Hyden CS, Bottomley W, Vigouroux C, Magré J, Raymond-Barker P, Murgatroyd PR, Chawla A, Skepper JN, Chatterjee VK, Suliman S, Patch AM, Agarwal AK, Garg A, Barroso I, Cinti S, Czech MP, Argente J, O'Rahilly S, Savage DB. Partial lipodystrophy and insulin resistant diabetes in a patient with a homozygous nonsense mutation in CIDEC. EMBO Mol Med. 2009;1:280-7. https://doi.org/10.1002/emmm.200900037. 
20. Rajab A, Straub V, McCann LJ, Seelow D, Varon R, Barresi R, Schulze A, Lucke B, Lützkendorf S, Karbasiyan M, Bachmann S, Spuler S, Schuelke M. Fatal cardiac arrhythmia and long-QT syndrome in a new form of congenital generalized lipodystrophy with muscle rippling (CGL4) due to PTRF-CAVIN mutations. PLoS Genet. 2010;6:e1000874. https://doi.org/10.1371/journal. pgen.1000874.

21. Cabanillas R, Cadiñanos J, Villameytide JA, Pérez M, Longo J, Richard JM, Alvarez R, Durán NS, Illán R, González DJ, López-Otín C. Néstor-Guillermo progeria syndrome: a novel premature aging condition with early onset and chronic development caused by BANF1 mutations. Am J Med Genet A. 2011;155A:2617-25. https://doi.org/10.1002/ajmg.a.34249.

22. Writzl K, Maver A, Kovačič L, Martinez-Valero P, Contreras L, Satrustegui J, Castori M, Faivre L, Lapunzina P, van Kuilenburg ABP, Radović S, ThauvinRobinet C, Peterlin B, Del Arco A, Hennekam RC. De Novo Mutations in SLC25A24 Cause a Disorder Characterized by Early Aging, Bone Dysplasia, Characteristic Face, and Early Demise. Am J Hum Genet. 2017;101:844-55. https://doi.org/10.1016/j.j.jhg.2017.09.017.

23. Agarwal AK, Kazachkova I, Ten S, Garg A. Severe mandibuloacral dysplasiaassociated lipodystrophy and progeria in a young girl with a novel homozygous Arg527Cys LMNA mutation. J Clin Endocrinol Metab. 2008;93: 4617-23. https://doi.org/10.1210/jc.2008-0123.

24. Paolacci S, Bertola D, Franco J, Mohammed S, Tartaglia M, Wollnik B, Hennekam RC. Wiedemann-Rautenstrauch syndrome: A phenotype analysis. Am J Med Genet A. 2017;173:1763-72. https://doi.org/10.1002/ajmg.a.38246.

25. Ruijs MW, van Andel RN, Oshima J, Madan K, Nieuwint AW, Aalfs CM. Atypical progeroid syndrome: an unknown helicase gene defect? Am J Med Genet A. 2003;1 16A:295-9. https://doi.org/10.1002/ajmg.a.10730.

26. Piran P, Thomas J, Kunnakkat S, Pandey A, Gilles N, Weingast S, Burton D, Balucani C, Levine SR. Mobile Applications for Stroke (MAPPS) investigators. Medical Mobile Applications for Stroke Survivors and Caregivers. J Stroke Cerebrovasc Dis. 2019;12:104318. https://doi.org/10.1016/j. jstrokecerebrovasdis.2019.104318.

\section{Publisher's Note}

Springer Nature remains neutral with regard to jurisdictional claims in published maps and institutional affiliations.

Ready to submit your research? Choose BMC and benefit from:

- fast, convenient online submission

- thorough peer review by experienced researchers in your field

- rapid publication on acceptance

- support for research data, including large and complex data types

- gold Open Access which fosters wider collaboration and increased citations

- maximum visibility for your research: over $100 \mathrm{M}$ website views per year

At $\mathrm{BMC}$, research is always in progress.

Learn more biomedcentral.com/submissions 